\title{
I nnovative teaching strategy for promoting academic integrity in simulation
}

\author{
William Stuart Pope, Teresa Gore, Karol C. Renfroe \\ School of Nursing, Auburn University, Alabama, USA \\ Correspondence: William Stuart Pope. Address: 141 Miller Hall, Auburn, Alabama 36849-5505, USA. Email: \\ wsp0002@auburn.edu.
}

Received: July 25, 2012

Accepted: September 9, 2012

Online Published: January 9, 2013

DOI : $10.5430 /$ jnep.v3n7p30

URL: http://dx.doi.org/10.5430/jnep.v3n7p30

\begin{abstract}
Maintaining academic integrity is a universal problem and can be especially difficult when implementing a simulation scenario that must take place over several days. It became obvious to faculty that students scheduled in later sessions exceeded realistic expectations in their performances. In response to this, faculty created two scenarios (one psychiatric and one medical-surgical)with flexibility that provided each student a unique and challenging learning experience while guiding the facilitator along various pathways based on the student's actions in the scenario. This allowed the overall learning objectives to be maintained regardless of students sharing information from simulations scheduled on earlier dates. Adapting the scenario based on individual student's responses allowed each student to have a unique learning opportunity in spite of the students being "prepped” by students that had already participated in the simulation. Faculty and student feedback revealed the flexibility of the scenarios was a valuable and meaningful learning experience. This paper discusses how to plan and implement this innovative approach to simulation, which will help to counter the effects of information sharing among students.
\end{abstract}

\section{Key words}

Academic integrity, Innovation, Simulation

\section{Introduction}

The use of simulation has proliferated in nursing education and many curriculums are designed to integrate simulation into every course. The nursing profession is regarded as highly principled but academic dishonesty has shown a positive correlation with the increased use of technology in education, including simulation ${ }^{[1]}$. Research has also connected unprincipled classroom behavior and unprincipled clinical behavior ${ }^{[1-6]}$. Maintaining academic integrity is a universal problem and can be especially difficult when implementing a simulation scenario that must transpire over several days for all students to participate.

\section{Problem identification}

Baccalaureate nursing students at a large southeastern land grant university have simulation experiences integrated within all clinical courses. It was becoming obvious to faculty that students scheduled for later simulation sessions exceeded 
realistic expectations in their performances. The faculty suspected that the students in earlier assigned groups were passing information to the later assigned groups. During debriefing sessions, some students revealed that they indeed had been given information about the scenarios from fellow students and were told the key specific differential diagnosis.

This paper describes how faculty at a School of Nursing implemented innovative strategies within simulation experiences to help counter the effects of information sharing that threatens academic integrity within these important learning activities.

\section{Review of literature}

Academic integrity has been defined as "a commitment, even in the face of adversity, to five fundamental values: honesty, trust, fairness, respect, and responsibility” ${ }^{[7]}$. There is an abundance of evidence that reveals that the lack of academic integrity in nursing education is a continuing and growing problem ${ }^{[3,4,8-20]}$. Brown ${ }^{[9]}$ reported that 8-39\% of nursing students had cheated. Ninety-five percent of those admitting to cheating reported that they had never been caught ${ }^{[21]}$. The profusion of academic dishonesty is compounded by the increased use in technology ${ }^{[1]}$. However, there is insufficient literature that focuses on cheating or dishonesty in the area of simulation.

Arhin ${ }^{[8]}$ reported that the issue of academic integrity may stem from the large variability between what students and faculty perceive as cheating. The largest percentage of students that had difficulty identifying dishonest behavior was in laboratory situations and identified their behavior as creative and using available resources. Various methods have been used in the classroom to decrease academic dishonesty in the university setting: increasing the number of proctors during testing, no use of electronic devices, using different versions of the test, and emphasizing honor codes ${ }^{[20]}$. Fontana ${ }^{[2]}$ reported that nurse educators that became aware of academic dishonesty acknowledged it as a liability and revealed that confronting and reporting students involved significant risk, but may underscore nurse educators' ethical responsibility to the nursing profession.

The conceptual framework for teaching simulation in this school of nursing is based on the NLN/Jeffries Simulation Model ${ }^{[22]}$ that was developed for use in nursing education in order to design, implement, and evaluate simulation experiences. This model depicts the triadic relationship of students, faculty, and educational practices influence on the simulation design and desired outcomes. The educational practices utilized in this school of nursing are designing simulation experiences to reinforce incorporation of didactic information into the clinical setting using evidence-based practices.

\section{Simulation experiences: Problem identified}

The following describes the setting and situations that prompted faculty discussion and activities implemented to improve academic integrity within simulation experiences.

The student population involved in these simulations included students in the second and third semester of a five clinical semester undergraduate baccalaureate-nursing program. All students enrolled in medical-surgical and psychiatric/mental health courses were required to participate in simulation as a requirement of the course. During their second semester, students $(\mathrm{n}=66)$ in their first semester medical-surgical course participated in the high fidelity medical-surgical scenario. These same 66 students participated in the psychiatric/mental health scenario during their third semester. All simulations at this institution were scheduled to occur over a time of several weeks due to limited physical space and resource constraints (see Table 1 and 2). 
Table 1. Simulation Effectiveness Tool (SET) Validity

\begin{tabular}{lll}
\hline Test & Results with 5-point Likert-type Scale & Results with 3-point Likert-type Scale \\
\hline Chronbach's Alpha & .92 with SEM of 2.84 & .929 \\
Learning & .87 & .873 \\
Confidence & .84 & .885 \\
\hline
\end{tabular}

Table 2. METI Simulation Effectiveness Tool ( $\mathrm{n}=66)$

\begin{tabular}{llll}
\hline Question & Do Not Agree & Somewhat Agree & Strongly Agree \\
\hline 1. I feel better prepared to care for real patients & $8 \%$ & $29 \%$ & $63 \%$ \\
2. I feel more confident in my decision making skills & $6 \%$ & $29 \%$ & $65 \%$ \\
$\begin{array}{l}\text { 3. I feel more confident that I will be able to recognize changes in my } \\
\text { real patient's condition }\end{array}$ & $7 \%$ & $24 \%$ & $69 \%$ \\
$\begin{array}{l}\text { 4. I am able to better predict what changes may occur with my real } \\
\text { patients }\end{array}$ & $10 \%$ & $26 \%$ & $64 \%$ \\
5. I was challenged in my thinking and decision-making skills & $2 \%$ & $27 \%$ & $71 \%$ \\
6. Debriefing and group discussion were valuable & $3 \%$ & $16 \%$ & $81 \%$ \\
\hline
\end{tabular}

\section{Medical surgical scenario}

A medical-surgical simulation was designed with the objective of students identifying and intervening appropriately for a post-operative complication. The focus of the simulation was deep vein thrombosis (DVT). The simulation was scheduled for 20-30 minutes and debriefing for 30 minutes. A high-fidelity manikin was moulaged to be a 65 year-old white female status post abdominal surgery third day. She had a history of hypertension, obesity, and was a current cigarette smoker. At the beginning of the simulation, the patient was not wearing her anti-embolic hose or sequential compression devices (SCD) and had refused ambulation the prior evening. The patient repeatedly stated she was in pain. If the participants conducted the seven variables of pain, the patient rated her pain six out of ten in her right leg and two out of ten for her abdominal incision. Her right leg was moulaged to reveal swelling, redness, and increased temperature indicating a DVT.

An issue was identified during later simulation sessions when some students immediately pulled back the covers and only assessed the right leg when the patient stated she was in pain. The faculty identified this trend and changed the patient complaint to some shortness of breath with the development of bibasilar crackles. The focus changed to atelectasis and not DVT. When faculty questioned the students, they denied any sharing of information, but it was obvious that the problem identification was established prior to systematic assessment protocols. This prompted faculty discussion to intervene and emphasize academic integrity as a critical component within simulation experiences.

The following semester a psychiatric simulation was planned. Faculty discussed the issue within the medical surgical scenario and suspicion of students scheduled for earlier simulations sharing information regarding the simulation with students in later simulations. More detailed observation of potential issues were warranted.

\section{Psychiatric scenario}

During the psychiatric scenario development, the faculty established the objectives for the participants: 1) to use effective therapeutic communication; 2) to conduct appropriate assessments and interviews; 3) to identify the symptoms of substance withdrawal in an elderly patient; develop an appropriate plan of care. The patient was a 73 year-old white female widow who lived alone. She had a history of congestive heart failure (CHF), hypertension and post-traumatic stress disorder. The scenario begins on the third day of hospitalization for an exacerbation of CHF. She had one living daughter and another daughter that died in an automobile accident in which the patient was the driver. She stated that she was a Southern Baptist and denied alcohol use on the admission assessment; however, she consumed 8-12 ounces of alcohol each night at bedtime and a home medication of Xanax that was not continued in the hospital. 
The psychiatric simulation incorporated a hybrid design: a high-fidelity manikin was used for the patient and a standardized participant, a graduate teaching assistant, was used for the daughter who was at the bedside. The patient and her daughter would provide enough information along with the symptoms for students to recognize withdrawal symptoms if the students used appropriate assessment techniques and therapeutic communications (interviewing skills) to gain needed information. The simulation was scheduled for one hour, with 20-30 minutes for the patient interaction and 30-40 minutes for debriefing. Similar to the medical/surgical simulation experiences, students scheduled in the later groups began to exceed expectations. Students identified alcohol withdrawal as the problem without appropriate assessment or interview.

The faculty facilitator confronted a group of students during their debriefing about their identification of alcohol withdrawal without questioning the patient about alcohol use. After discussing their performance and identifying of alcohol withdrawal without use of appropriate interviewing techniques, the group of students confirmed the faculty suspicion that information had been shared by groups that had participated in an earlier session.

\section{Simulation experiences: Teaching strategies adapted}

It became apparent from faculty observations and students confirming that information sharing was initiated during some simulation experiences, that changes needed to be implemented. One change was directed to the core problem of academic integrity and the other to the teaching approaches within simulation experiences.

\section{Addressing Academic I ntegrity}

Based on these discoveries, the faculty addressed the subject of information sharing and academic integrity both formally and informally with the students. Adjustments were made in the orientation to simulation and developing the simulation scenarios. This included initiating a Professional Integrity and Confidentiality Agreement that students are required to sign in the first semester of the curriculum. The Confidentiality Agreement clearly states the sharing of simulation information negatively affects the learning opportunity of future participants and is a breach of the academic code. This breach of academic code is viewed on the same level of offense as cheating on a test or plagiarism.

\section{Adapting simulation teaching strategies}

Simulation scenarios were adjusted and re-designed to be adaptable so changes could be initiated based on student responses and performance. For example, the DVT could be changed to atelectasis once the patient complained of pain after abdominal surgery and the student went to assess the leg without asking location of pain. .

The psychiatric scenario was altered to focus on withdrawal from Xanax/Alprazolam, which was part of the home medication regimen that was not continued in the hospital. This allowed for change in the focus of the simulation while maintaining objectives for substance withdrawal identification and developing a plan of care. In both scenarios, if the students followed the proper process the scenario continued as planned. If students exceeded realistic expectations or did not follow appropriate interviewing and assessment skills, the scenario was adjusted to maintain the integrity of the simulation but provide a different focus of the problem.

\section{Discussion}

Providing quality learning experiences for students is the primary goal for faculty. The faculty recognized that for some students the quality of the learning experience had been compromised. This prompted faculty to discuss this issue during debriefing. Once questioned, the students admitted some were indeed sharing information among groups. It was apparent in the discussions that the students did not recognize this as cheating. Both those who gave and received information simply perceived it as being helpful. Further, they had no concept that sharing information was robbing another of a learning opportunity and a form of academic dishonesty. These findings are congruent with the pilot study conducted by 
Arhin in 2009 which indicated that nursing students understood the definition of academic dishonesty in examination, but had difficulty identifying academic dishonest behaviors outside of these testing situations.

The emphasis that was placed on academic integrity and signing the confidential agreement has reduced but did not eliminate the incidence of information sharing. Therefore, the faculty continues the practice of creating scenarios that are easily adjusted based on the students assessment and performance while maintaining the original learning objectives. This dual innovative approach, the confidentiality agreement and flexible scenarios, counters the effects of information sharing and helps maintain academic integrity in simulation.

The initial response faculty identified to combat the academic dishonesty was the creation of scenarios that were easily adjusted based on the students' assessment and performance while maintaining the original learning objectives. This strategy provided the facilitator with guidance and the ability to provide an equal learning opportunity to each student, even those participating later in the experience.

The students were informed the simulation environment was a quality safe environment where no harm would come to actual patients and an opportunity that errors could occur without judgment or patient harm. A discussion was conducted on learning from our successes and mistakes. Simulation provided the students with an opportunity to observe the responses of a patient to appropriate and inappropriate interventions and plans. Upon implementation of this strategy, faculty noted a drastic reduction in the occurrence of students exceeding expectations in later simulation session. Therefore, the faculty has continued the dual approach of the academic integrity and confidentiality agreement along with flexible scenarios. These measures assisted the faculty's efforts to counter the effects of information sharing and helped maintain academic integrity in simulation.

\section{Conclusion}

Lack of academic integrity is a growing problem in nursing education. This problem certainly exists in the area of simulation. The innovative planning of flexible simulation scenarios lessens the ramifications that information sharing has on student learning. Defining academic integrity and emphasizing its importance from the beginning of the professional program have achieved a heightened awareness of the harm created by academic dishonesty. By incorporating these strategies, faculty has improved the quality of the simulation learning experience for all students.

\section{References}

[1] Harper, M. G. High tech cheating. Nurse Education Today. 2006; 26: 672-679. PMid:17014934 http://dx.doi.org/10.1016/j.nedt.2006.07.012

[2] Fontana, J. S. Nursing faculty’s experience of student’s academic dishonesty. Journal of Nursing Education. 2009; 48(4): $181-185$. PMid:19441633 http://dx.doi.org/10.3928/01484834-20090401-05

[3] Fosbinder, D. Cheating and plagiarism [Editorial]. Nurse Educator.1991; 16(6): 5. PMid:1754140 http://dx.doi.org/10.1097/00006223-199116060-00002

[4] Kenny, D. Student plagiarism and professional practice. Nurse Education Today. 2007; 27(1): 14-18. PMid:16624455 http://dx.doi.org/10.1016/j.nedt.2006.02.004

[5] Kiehl, E. M. Using an ethical decision-making model to determine consequences for student plagiarism. Journal of Nursing Education. 2006; 45(6): 199-203. PMid:16780007

[6] Langone, M. Promoting integrity among nursing students. Journal of Nursing Education. 2007; 46(1): 45-47. PMid:17302100

[7] Center for Academic Integrity. The fundamental values of academic integrity (1999). Available from: http://www.academicintegrity.org/fundamental values project/ pdf/ FVProject.pdf (15 July 2011, date last accessed).

[8] Arhin, A. A pilot study of nursing student's perceptions of academic dishonesty: A generation Y perspective. ABFN Journal. 2009; 20(2): 17-21. 
[9] Brown, D. Cheating must be okay. Everybody does it! Nurse Educator. 2002; 27: 6-8. PMid:11840063 http://dx.doi.org/10.1097/00006223-200201000-00010

[10] Gaberson, K. Academic dishonesty among nursing students. Nursing Forum. 1997; 32(3): 14-20. PMid:9362877 http://dx.doi.org/10.1111/j.1744-6198.1997.tb00205.x

[11] Hilbert, G. Involvement of students in unethical classroom and clinical behaviors. Journal of Professional Nursing. 1985; 1: 230-234. http://dx.doi.org/10.1016/S8755-7223(85)80160-5

[12] Hilbert, G.A. Academic fraud: Prevalence, practices, and reasons. Journal of Professional Nursing. 1987; 3: 39-45. http://dx.doi.org/10.1016/S8755-7223(87)80026-1

[13] Hilbert, G. Moral development and unethical behavior among nursing students. Journal of Professional Nursing. 1988 ; 4: $163-167$. http://dx.doi.org/10.1016/S8755-7223(88)80133-9

[14] Kolanko, K. M., Clark, C., Heinrich, K. T., Olive, D., Serembus, J. F. M., \& sifford, S. Academic dishonesty, bullying, incivility, and violence: Difficult challenges facing nurse educators. Nursing Education Perspectives. 2006; 27(1): 34-43. PMid:16613130

[15] Prescott, P.A. Academic misconduct: Considerations for educational administrators. Journal of Professional Nursing. 1989; 5(5): 283-287. http://dx.doi.org/10.1016/8755-7223(89)90041-0

[16] Roberts, E. F. Nursing faculty’s handling of academic dishonesty. Nursing Connections. 1999; 12(2): 13-22. PMid:10690112

[17] Schmidt, S.D. Cheating: An ethical concern for nurse educators [Electronic version]. Alabama Nurse. 2006; 33(1): 1, 4.

[18] Schmitz, K., \& Schaffer, M. Ethical problems encountered in the teaching of nursing: Student and faculty perceptions. Journal of Nursing Education. 1995; 34: 42-44. PMid:7876911

[19] Tanner, C.A. Moral decline or pragmatic decision making? Cheating and plagiarism in perspective. Journal of Nursing Education. 2004; 43(7): 291-292. PMid:15303580

[20] Tippitt, M. P., Ard, N., Kline, J. R., Tilghman, J., Chamberlain, B., \& Meagher, P. G. Creating environments that foster academic integrity. Nursing Education Perspectives. 2009; 30(4): 239-244. PMid:19753858

[21] Johnson, S., \& Martin, M. Academic dishonesty: A new twist to an old problem. Athletic Therapy Today. 2005; 10(4): 48-50.

[22] Jeffries, P. R. (Ed.). Simulation in nursing education: From conceptualization to evaluation. New York: National League of Nursing, 2007.

[23] Medical Education Technologies, Inc. Simulation effectiveness tool. 2010. Available from: http://www.meti.com/mymeti/education_main.html (26 September 2010, date last accessed). 